Etnográfica

Revista do Centro em Rede de Investigação em

Antropologia

vol. 23 (1) | 2019

Vol. $23(1)$

\title{
Transnacionalização evangélica brasileira para a Europa: significados, tipologia e acomodações
}

Brazilian evangelical transnationalization towards Europe: meanings, typology, and accommodations

\section{Ari Pedro Oro}

\section{(2) OpenEdition}

\section{Journals}

Edição electrónica

URL: https://journals.openedition.org/etnografica/6229

DOI: 10.4000/etnografica.6229

ISSN: 2182-2891

\section{Editora}

Centro em Rede de Investigação em Antropologia

\section{Edição impressa}

Data de publição: 1 fevereiro 2019

Paginação: 5-25

ISSN: 0873-6561

\section{Refêrencia eletrónica}

Ari Pedro Oro, «Transnacionalização evangélica brasileira para a Europa: significados, tipologia e acomodações», Etnográfica [Online], vol. 23 (1) | 2019, posto online no dia 21 março 2019, consultado o 20 janeiro 2022. URL: http://journals.openedition.org/etnografica/6229 ; DOI: https://doi.org/ 10.4000/etnografica.6229

\section{(c) (i) (8)}

Etnográfica is licensed under a Creative Commons Attribution-NonCommercial 4.0 International License. 


\section{Transnacionalização evangélica brasileira para a Europa: significados, tipologia e acomodações}

\section{Ari Pedro Oro}

Este artigo versa sobre a transnacionalização de igrejas evangélicas brasileiras que há algumas décadas realizam a "missão invertida" para a Europa. Analisa os significados agregados a este processo, sugere uma tipologia de transnacionalização religiosa, composta de quatro diferentes modelos e, enfim, discorre sobre as dinâmicas e práticas das igrejas brasileiras para superarem as diferenças culturais e se acomodarem às culturas europeias.

PALAVRAS-CHAVE: transnacionalização religiosa, igrejas evangélicas, pentecostalismo, Europa.

Brazilian evangelical transnationalization towards Europe: meanings, typology, and accommodations - This article aims to examine the transnationalization of Brazilian evangelical churches that many decades ago accomplish the "reverse mission" to Europe. We analyze the meanings linked to this process, we suggest a typology of religious transnationalization composed of four different models, and finally we explain the dynamics and practices undertaken by these Brazilian churches to overcome cultural differences and to adapt to the European cultures.

KEYWORDS: religious transnationalization, evangelical churches, Pentecostalism, Europe.

ORO, Ari Pedro (arioro@uol.com.br) - Programa de pós-graduação em Antropologia Social, Universidade Federal do Rio Grande do Sul, Brasil. 


\section{A "MISSÃO INVERTIDA" PARA A EUROPA CONSTITUI UMA PRÁTICA} realizada por várias igrejas evangélicas brasileiras que, para tanto, se apoiam na ideia segundo a qual a Europa perdeu a sua potência espiritual cristã, necessitando, consequentemente, ser recristianizada. ${ }^{1}$ É este papel que algumas igrejas brasileiras se atribuem, transnacionalizando-se especialmente para Portugal, Itália e Inglaterra. ${ }^{2}$

Neste texto, após aclarar os conceitos aqui utilizados, discorro sobre os significados agregados à missão invertida pelas igrejas evangélicas brasileiras, na perspectiva Brasil-Europa. Para tanto, levo em consideração os discursos produzidos pelos agentes religiosos, mas, também, os seus subentendidos e os seus não ditos. Na sequência, mostro que a transnacionalização religiosa implementada pelas diferentes igrejas não ocorre em todas da mesma maneira. A diversidade de fluxos permite construir uma tipologia formada por quatro modelos de transnacionalização, os quais, embora necessariamente incompletos e provenientes do campo evangélico, poderão encontrar recorrências nas dinâmicas transnacionais que envolvem outros segmentos religiosos. Enfim, noto que, apesar dos diferentes desdobramentos transnacionais perpetrados pelas igrejas brasileiras na Europa, elas coincidem na preocupação com a adaptação às culturas locais, contribuindo, assim, para corroborar e ampliar a "importância do Brasil na nova cartografia religiosa global" (Rocha e Vásquez 2016: 7$).^{3}$

Desta forma, este texto procura responder sobretudo a três questões: quais são os sentidos implicados na transnacionalização de igrejas evangélicas brasileiras para a Europa, como essas igrejas viabilizam e executam a transnacionalização para a Europa, e como elas negociam as diferenças visando a sua adaptação às culturas europeias?

Os dados empíricos aqui utilizados derivam de pesquisas que venho realizando no Sul do Brasil há aproximadamente dez anos junto ao segmento evangélico, bem como de uma pesquisa de campo realizada na Itália, em outubro de 2014 e em maio de 2015, e em Portugal, em outubro de 2016 e em

l Este texto resulta de pesquisa realizada no âmbito da bolsa produtividade/CNPq "Transnacionalização evangélica brasileira para a Europa: tensões e adaptações".

2 A missão invertida constitui uma prática também realizada pela parcela carismática da Igreja Católica do Brasil, sobretudo a comunidade Canção Nova, a qual tem enviado missionários para a Europa e os Estados Unidos, obedecendo à lógica de convites e contando sempre com a autorização da hierarquia católica local, sobretudo da autoridade episcopal (Carranza e Mariz 2016; Gabriel 2010). Para além do campo cristão, países europeus, como Portugal, também têm recebido a atenção de agentes afro-religiosos que implantaram ou contribuíram para a instalação da Umbanda e de outras expressões afro-religiosas em território lusitano (Pordeus Junior 2009; Saraiva 2010; para uma análise da diáspora das religiões afro-brasileiras na Europa, ver Saraiva 2017).

3 Para Rocha e Vásquez, países como o Brasil, a Nigéria e o Gana, apesar da posição subalterna que ocupam no sistema capitalista mundial, "começaram a desempenhar um papel de liderança na globalização religiosa" (2016: 19). 
outubro de 2017. Nestas etapas de campo adotei as técnicas antropológicas de investigação, como a observação participante em reuniões e cultos e entrevistas semidirigidas. $\mathrm{Na}$ Itália entrevistei um pastor italiano e cinco brasileiros e em Portugal cinco brasileiros e sete portugueses, totalizando dezoito agentes religiosos entrevistados. ${ }^{4}$ Portanto, as ideias avançadas neste texto derivam sobretudo dos dados colhidos nesses dois países europeus, embora aqui também figurem referências coletadas no Brasil sobre as experiências das igrejas brasileiras na Grã-Bretanha.

\section{ESCLARECENDO OS CONCEITOS}

A "missão invertida" (Freston 2010), ou "evangelização ao contrário" (Mary 2008), ou, ainda, "evangelização de retorno" (Trombetta 2013), constitui uma prática que envolve não somente igrejas evangélicas brasileiras, mas também latino-americanas e africanas (Argyriadis et al. 2012; Oro, Steil e Rickli 2012). Este fenômeno pode ser assim definido: "aqueles que um dia foram objeto de missão, catequisados nas colônias, invertem o fluxo histórico, enviando missionários para as metrópoles, com a consigna de converter a seus cidadãos" (Carranza e Mariz 2013: 29).

Como Paul Freston (2010) destacou, a "missão invertida" não consiste somente numa inversão geográfica, sul-norte. Ela é também social, no sentido de que provém "de baixo", invertendo as posições no mapa mundial, assemelhando-se à expansão do cristianismo dos primeiros tempos. Seria, como frisam Ruiz e Michel (2012: 135), "une forme de revanche historique du colonisé sur le colonisateur".

A missão invertida é realizada mediante a transnacionalização de igrejas e de seus agentes religiosos, que deixam o local (Brasil, América Latina, África) para se instalarem em outras nações, no caso europeias. Diferentemente da

4 Na Itália entrevistei os seguintes pastores: Ugo Sottile, italiano, da Assembleia de Deus, em 05/05/2014; os brasileiros Edilson Avila e Ana Avila, da Igreja Maanaim, em 11/05/2014; Anderson Mello, da Universal, em 07/05/2014; João Bottega, da Batista, em 09/05/2014; Junior, da Assembleia de Deus, em 15/05/2014. Em Portugal entrevistei os pastores brasileiros Carlos Xavier, da Igreja Batista Brasa, em 13/10/2016 e em 15/10/2017; João Neto, da Igreja Sal da Terra, em 12/10/2016; Sidson Novais, da Missão Cristã Internacional, em 11/10/2016; o pastor responsável da Igreja Mundial do Poder de Deus em Portugal, em 09/10/2017; o pastor Rubem, da Universal, em 13/10/2017; e ainda os pastores portugueses Mario Boto e Richard Rodrigues, da Hillsong, em 08/10/2017; Rodrigues Pereira, da Missão Cristã Internacional e vice-presidente da Aliança Evangélica portuguesa, em 11/10/2017; Nuno Fernandes e Ana Mary Baizan, da Assembleia de Deus, em 11/10/2017; João Vilaça, da Igreja Metodista, em 18/10/2017; Rui Maia Fonseca, da Igreja Pentecostal Shalom, em 19/10/2017. Neste texto, todos os depoimentos dos agentes acima mencionados que nele comparecerão resultam das entrevistas realizadas nas datas referidas. Além dos contatos com pastores na Europa, farei uso de entrevistas realizadas no Brasil com uma dezena de pastores que serão mencionados ao longo do texto. 
globalização, que constitui uma "transnacionalização pelo alto", 5 os fluxos internacionais que envolvem igrejas constituem uma "transnacionalização por baixo", a qual, no dizer de Guarnizo e Smith (1998: 5), faz referência a "conscious and successful efforts by ordinary people to escape control and domination 'from above' by capital and the state". Por isso mesmo, Capone e Mary (2012: 30) destacam a dimensão política da transnacionalização. Ela constitui um "espace politique contre-hégémonique qui déplace le jeu des discriminations imposées par le haut", constituindo um complemento ou o reverso da mundialização econômica e tecnológica. ${ }^{6}$

A transnacionalização possui duas características principais. Em primeiro lugar, como sustenta Daniel Alves (2011: 32), ela se refere a fluxos de pessoas que se juntam em "redes de relações [...] com níveis de institucionalização variáveis, atravessando espaços societários diferentes"; e, em segundo lugar, como sublinham Badie e Smouts (1995), ela mantém fraca (ou nenhuma) relação com os aparelhos de Estado, embora isto dependa da situação legal e conjuntural que vigora em cada país.

Enfim, é importante reter que neste texto a referência às igrejas evangélicas brasileiras que se transnacionalizam para a Europa não recai sobre as denominações históricas da reforma protestante, mas sobre aquelas do amplo segmento pentecostal ou renovado.

Como se sabe, o pentecostalismo pode ser interpretado como um movimento que se desenvolveu em três ondas. ${ }^{7}$ As igrejas que irão comparecer neste texto figuram majoritariamente na terceira onda, também conhecida como movimento neopentecostal. São elas: Igreja Universal do Reino de Deus, Mundial do Poder de Deus, Sara Nossa Terra, Maanaim, Missão Cristã

5 Segundo o antropólogo argentino Alejandro Frigerio, a globalização seria uma "transnacionalização pelo alto", posto que ela "descreve os esforços das corporações multinacionais, da mídia e de outras elites sociais poderosas para estabelecer dominação política, econômica e social no mundo" (Frigerio 2013: 19).

6 O caráter contra-hegemônico da transnacionalização religiosa é, neste texto, apenas apontado, sabendo, porém, como também destacou um dos avaliadores do presente artigo para esta revista, que se trata de um aspecto significativo do fenômeno aqui abordado. Porém, por falta de espaço neste texto e por constituir um tópico que merece uma reflexão teórica própria e aprofundada, será objeto de um outro artigo.

7 A primeira onda surgiu no início do século XX, nos Estados Unidos, e caracteriza-se pela formação da comunidade de crentes que se reuniam na comunhão do falar em línguas e acreditavam na volta iminente de Cristo. A segunda foi inaugurada nas décadas de 1950-1960 quando surgiram as primeiras igrejas nacionais, que passaram a realizar proselitismo através da rádio e introduziram o evangelismo de massas, centrado nos rituais de cura divina. A terceira onda surgiu a partir da década de 1970 quando o pentecostalismo se inseriu na esfera pública com o uso das mídias, especialmente da televisão, e com o ingresso no político-institucional, nos países em que isto é possível, além de introduzir a flexibilização dos costumes - em relação às normas puritanas constantes nas ondas pentecostais precedentes - e dar ênfase às teologias da prosperidade e da guerra espiritual. O termo hoje bastante utilizado de neopentecostalismo é geralmente aplicado ao pentecostalismo da terceira onda. 
Internacional, Luz para os Povos e Sal da Terra. Mas há, também, uma igreja tida como renovada (Batista Brasa) e uma da primeira onda (Assembleia de Deus).

\section{OS SIGNIFICADOS DA TRANSNACIONALIZAÇÃO RELIGIOSA}

Há uma diferença de escala associada à política dos significados atribuídos pelas igrejas evangélicas brasileiras ao envio de missionários para a Europa. O significado mais verbalizado repousa na ideia de recristianizar a Europa.

\section{Recristianizar a Europa}

A narrativa recorrente nos meios evangélicos brasileiros que se transnacionalizam para a Europa parte de um diagnóstico: vigora na atualidade, neste continente, um grande "esfriamento espiritual", resultante do apego ao materialismo, ao hedonismo e ao individualismo. É o preço pago pela adesão à modernidade: o enxugamento da dimensão espiritual que, em se tratando da Europa, significa a sua descristianização.

Diante desta situação, consideram os líderes evangélicos brasileiros que não podem permanecer passivos. Ao contrário, como sintetiza o pastor Dilermando, da Igreja Maanaim, de Porto Alegre, ${ }^{8}$ faz-se necessário encetar esforços para "reconquistar espiritualmente a Europa". É tão forte esta pretensão que esse pastor chega a afirmar: "minha preocupação hoje não é evangelizar o Brasil; hoje minha preocupação é evangelizar a Europa”.

Por seu turno, o pastor Bazerque, responsável pela área de missões da Igreja Batista Brasa, ${ }^{9}$ considera que os europeus foram os "pais" do Norte que trouxeram o evangelho para os "filhos" do Sul, tendo agora "chegado a hora de nós, filhos, voltarmos aos pais, auxiliarmos os pais, fortalecermos os pais". Trata-se, segundo ele, de uma missão que parte dos confins do mundo: "Os confins do mundo é que estão fazendo essa mesma rota, voltando para a Europa". ${ }^{10}$

Também o pastor Locatelli, da Assembleia de Deus de Porto Alegre, afirma que o Brasil possui uma dívida em relação à Europa. Isto porque os europeus trouxeram a mensagem religiosa que aqui foi guardada e cresceu. Para ele, a missão invertida é a devolução do que "eles nos deram, porque hoje eles vivem

8 O pastor Josué Dilermando fundou no ano 2000 a Igreja Maanaim, localizada em Porto Alegre. Possui hoje cerca de 300 fiéis. Segundo ele, "o problema da Europa é a modernidade, o pensamento moderno e a secularização, o racionalismo e o individualismo. Este pensamento não agrada a Deus" [entrevista realizada em 14/10/2013].

9 A Igreja Batista Brasa surgiu em Porto Alegre em 1986, como resultado de um processo de renovação ocorrido no interior da Primeira Igreja Batista Brasileira. Possui templos em várias cidades do Sul do Brasil e também em Portugal, como veremos a seguir.

10 Entrevista realizada em Porto Alegre em 09/11/2011. 
o que talvez uma vez a gente viveu aqui, no passado. Estamos pagando uma dívida". ${ }^{11}$

Portanto, esse é o principal discurso que circula no meio evangélico brasileiro para justificar o envio de missionários para a Europa: haveria, neste continente, uma falência espiritual que interpela moralmente as igrejas locais para investirem na prática missionária visando a sua recristianização. No entanto, além deste significado há outros menos explicitados para a condução da missão invertida para a Europa, os quais atingem, evidentemente, as igrejas e os missionários em graus diferenciados.

\section{Auferir benefício econômico e se abrir para o mundo}

Não se pode desprezar o interesse econômico que alimenta algumas igrejas e certos pastores a desembarcarem na Europa, não sendo isto, porém, incompatível com o trabalho missionário, inscrito na lógica da fluidez entre o religioso e o econômico. Neste sentido, por exemplo, declara o pastor Valdeci, da Assembleia de Deus, de Porto Alegre: "Elas [as igrejas europeias] pagam muito bem os que vão lá e pregam a palavra de Deus. Vale a pena”. ${ }^{12} \mathrm{O}$ depoimento do renomado músico evangélico radicado em Porto Alegre Asaph Borba vai na mesma direção: “Tenho um amigo que voltou da Noruega, ficou cinco anos lá e voltou bem. Tá comprando uma casinha aqui. Trouxe um dinheirinho de volta e tá como missionário". ${ }^{13}$

Mas não são somente os agentes religiosos que se beneficiariam dos trabalhos missionários na Europa. Possivelmente a mesma lógica utilitarista visando a obtenção de algum benefício econômico é adotada, embora de forma não diretamente enunciada, por algumas igrejas que se transnacionalizam para a Europa. É o que sugere o pastor Rodrigues Pereira, vice-presidente da Aliança Evangélica Portuguesa, a partir de depoimentos de líderes de igrejas brasileiras instaladas na Europa que afirmam buscarem na Europa "autonomia" (financeira) em relação às matrizes brasileiras. "Por quê - pergunta-se ele - essas mesmas igrejas brasileiras que enviam missionários para a África, não procedem lá da mesma forma e sustentam durante anos os seus missionários?" E arremata afirmando que "o espírito missionário é incompatível com o interesse econômico. Buscar autonomia (econômica) não é ser portador do coração missionário".

Outro significado ligado à missão invertida, também ele pouco presente nas narrativas dos agentes religiosos, concerne a possibilidade de sujeitos brasileiros, muitos deles pertencentes às camadas baixas e médias-baixas, viajarem para o exterior, manterem contatos internacionais e se sentirem ligados a países

11 Conforme entrevista concedida a Mariana Picolotto em 13/10/2011. As demais falas deste pastor constantes neste texto resultam desta entrevista.

12 Entrevista concedida a Mariana Picolotto em 11/06/2011.

13 Entrevista realizada em Porto Alegre em 09/1 1/2013. 
tidos como do Primeiro Mundo. Assim, da mesma forma como historicamente os pentecostalismos permitiram a muitas pessoas o acesso à leitura, à política e às mídias, eles abrem hoje aos seus membros os horizontes da Europa e do mundo. O pentecostalismo seria, assim, como sublinham Ruiz e Michel (2012: 15), "l'un des espaces privilégiés de production du 'global" ".

Porém, do ponto de vista antropológico há outro importante significado associado à "missão invertida" para a Europa. Trata-se da possibilidade de obtenção de um plus de legitimidade no contexto religioso concorrencial "local".

\section{Recurso simbólico de legitimidade}

Como se sabe, as relações entre as igrejas pentecostais, independentemente do seu tamanho, são de concorrência, aberta ou velada, pela conquista de fiéis. Neste contexto, o investimento na circulação internacional por países europeus tornou-se um importante elemento simbólico de fortalecimento de legitimidade, devido à imagem construída sobre a Europa neste e em outros meios religiosos, pois ela é tida como moderna, berço do cristianismo e origem de muitos revivalismos religiosos.

Assim, as igrejas locais que conseguem enviar missionários para a Europa nutrem um sentimento de elevação de status, observável na ênfase dada a esses fluxos nos cultos e, especialmente, nos jornais e páginas virtuais das igrejas. Neste contexto, igrejas e pastores estão persuadidos de ganharem pontos nas disputas simbólicas que mantêm com outros pastores e igrejas locais que não possuem parcerias globais, sobretudo com países europeus.

Nota-se, pois, que as igrejas que participam dos circuitos transnacionais abrem-se para o "global" para se reforçarem no "local", para ganharem pontos "aqui", diante da concorrência "local". Assim, como frisei em outro lugar (Oro 2014a), além da articulação entre o "local" e o "global", nota-se uma certa instrumentalização do "global" pelo "local". Se esta análise estiver correta, pode-se traduzir a expressão nativa "conquistar espiritualmente a Europa" por "conquistar legitimidade local".

Parece evidente, portanto, que além da narrativa nativa recorrente de "recristianizar a Europa", a missão invertida possui também outros significados, com destaque para o menos enunciado, qual seja, o reforço simbólico de legitimidade visando a elevação de prestígio no contexto concorrencial local. Como em todas as situações semelhantes, possivelmente são os significados não explicitados os maiores portadores de agência para alavancar a transnacionalização para a Europa.

\section{UMA TIPOLOGIA DE TRANSNACIONALIZAÇÃO RELIGIOSA}

Como foi dito no início do texto, a transnacionalização das igrejas brasileiras para a Europa não ocorre sempre da mesma maneira. Por isso mesmo, a 
pesquisa levada a efeito na Itália e em Portugal permite sugerir uma tipologia composta de quatro diferentes modelos de transnacionalização religiosa. Reitero que outras pesquisas mais aprofundadas devem revelar outras possibilidades de transnacionalização, ampliando, assim, a tipologia que passo a expor.

\section{Autonomia e exclusivismo}

O primeiro modelo resulta do modo de se transnacionalizarem algumas grandes igrejas neopentecostais brasileiras, especialmente a Universal do Reino de Deus, a Mundial do Poder de Deus e a Internacional da Graça de Deus. Essas igrejas implantam-se nos outros países por iniciativa própria e, uma vez neles instaladas, atuam como igrejas autônomas.

Tomemos o exemplo da Igreja Universal do Reino de Deus, fundada em 1977 no Rio de Janeiro por Edir Macedo, e sua implantação em Portugal. ${ }^{14}$

A chegada da Universal neste país ocorreu em 1989 e obedeceu à lógica da disputa por espaço e por fiéis no mercado religioso global. Ou seja, na ótica da igreja, Portugal consistia num "polo de expansão especialmente sedutor" (Mafra 2003: 165), por ser um possível consumidor dos bens e serviços oferecidos pela igreja, mas, especialmente, porque poderia servir de ponte para a expansão da igreja para outros países europeus e também africanos de língua portuguesa. ${ }^{15}$ Assim procedendo, no dizer de $\mathrm{H}$. Vilaça, a Universal, bem como a Igreja do Maná, "introduzem uma novidade no campo religioso português: orientam-se segundo uma lógica de mercado, funcionando por isso de um modo bastante competitivo" (Vilaça 2013: 85).

Em Portugal a Universal causou grande impacto, seja devido às suas práticas ritualísticas, que compreendem o exorcismo dos demônios e a demanda por dinheiro, seja pelo seu método, utilizado também no Brasil e alhures, de investir nas mídias e de locar ou comprar grandes espaços, sobretudo salas de espetáculos e cinemas, e transformá-los em templos (Oro e Tadvald 2015). Neste sentido, foram bastante polêmicas tanto a aquisição do cine-teatro Império, em Lisboa, em 1992, por vinte milhões de dólares, quanto a tentativa de compra da sala Coliseu na cidade do Porto, em 1995. Esta última investida, associada a outros fatores, contribuiu fortemente para a construção em Portugal de estigmas depreciativos sobre a Universal, que reverberaram nas demais igrejas evangélicas brasileiras que vieram posteriormente a se instalar no país, as quais tiveram que superar as barreiras derivadas do modus operandi da Universal (Gracino Junior 2016: 39). O depoimento do pastor português Rodrigues

14 Segundo o site da Universal, Portugal é o país da Europa onde esta denominação possui mais templos. Seriam 124. Ela ainda está presente em outros 20 países europeus. A sua presença internacional chegaria hoje a 104 países (ver < https://www.universal.org/a-universal > última consulta em dezembro de 2018).

15 A Universal não é a única igreja a atribuir a Portugal o sentido de porta de entrada para a Europa. A mesma lógica existe nas igrejas Mundial do Poder de Deus e Sara Nossa Terra, por exemplo. 
Pereira vai além: para ele, o impacto negativo causado pela Universal interferiu na aceitação das próprias igrejas evangélicas portuguesas em seu país.

Por outro lado, no entanto, Helena Vilaça (2016) chama a atenção para o fato de que todos os conflitos associados à Universal em Portugal trouxeram à baila, pela primeira vez, o debate sobre o pluralismo religioso e a diversidade de crenças no país. ${ }^{16}$

$\mathrm{Na}$ atualidade, há mais de uma centena de templos da Universal em Portugal, localizados majoritariamente no Centro-Sul do país, sobretudo na Grande Lisboa (Gracino Junior 2016: 271). Quanto ao número de fiéis, trata-se de uma estimativa difícil de realizar. Segundo o estudo intitulado "Identidades religiosas em Portugal: representações, valores e práticas, 2011 l”, o peso da Universal no campo religioso português é de 0,1\% e o dos evangélicos de 2,3\% (Vilaça 2013). Quanto ao perfil social dos fiéis, minha observação etnográfica confirma a afirmação de C. Mafra (2002), segundo a qual, de forma semelhante ao que ocorre no Brasil, há um predomínio de mulheres, pertencentes às camadas baixas, embora a Universal tenha também atraído um público pertencente às camadas médias-baixas. Em termos étnicos trata-se de uma membresia variada, formada, sobretudo, por portugueses, africanos de diferentes países, latino-americanos e brasileiros. ${ }^{17}$

Em Portugal, como também na Itália, a Universal não interage com outras igrejas cristãs, nem se integra em convenções ou organizações religiosas existentes nesses países. O mesmo procedimento é realizado pelas igrejas Internacional da Graça e Deus e Mundial do Poder de Deus. O pastor responsável por esta última igreja em Portugal disse-me, a este propósito: "eles na deles (Universal, Internacional) e nós na nossa. Mas honramos o mesmo Deus". ${ }^{18}$ Trata-se, assim, reitero, de igrejas fechadas em si mesmas, que sustentam o princípio do exclusivismo religioso. Relações ecumênicas nessas igrejas podem ocorrer em nível individual, mas raramente institucional.

\section{Parceria inicial, ruptura e implantação institucional}

O segundo modelo de transnacionalização é constituído por igrejas brasileiras que possuem como elemento desencadeador do processo uma parceria, geralmente informal, estabelecida com igrejas ou agentes religiosos europeus,

16 Também Donizete Rodrigues e Marcos Silva sublinham que a chegada das igrejas neopentecostais brasileiras em Portugal - com destaque para a Universal - contribuiu para o alargamento do campo religioso, "provocando, desta forma, rápidas e significativas mudanças religiosas na sociedade portuguesa" (2014: 103).

17 Em 2015, segundo dados do Ministério das Relações Exteriores, o número de brasileiros presentes em Portugal era de 166.000 indivíduos, representando 25\% do número de imigrantes estrangeiros radicados no país (Rocha e Vásquez 2016: 12-13).

18 Como referiu o pastor Xavier, da Igreja Batista Brasa, estas igrejas não participam, por exemplo, da Comunhão dos Pastores do Norte (de Portugal) “porque não querem; não é que nós não aceitamos”. 
mas que, posteriormente, separam-se deles e se instalam institucionalmente na Europa, embora no início isto não figurasse como projeto eclesial. Inscrevem-se neste modelo as igrejas brasileiras Batista Brasa, instalada em Portugal, e Maanaim, fixada na Itália.

A Igreja Batista Brasa, fundada, como disse, em Porto Alegre, em 1986, privilegia a ação missionária e atua internacionalmente segundo o modelo de parcerias interinstitucionais (Oro e Alves 2015). ${ }^{19}$

Chegou à cidade de Espinho, em Portugal, em 1993, após ter estabelecido relações com o pastor Leonel Ferreira, da Igreja de Cristo Evangélica Carismática Khárisma. Nos primeiros anos, missionários da igreja Brasa, inclusive o seu líder Jessé Guimarães, passaram temporadas em Espinho, sempre atuando junto à igreja Khárisma, ocupando-se sobretudo de um grupo de ciganos evangélicos. ${ }^{20}$ Mas, em 1996, a convite do líder dos ciganos, Rui Maia, ${ }^{21}$ que para tanto foi a Porto Alegre conversar pessoalmente com o pastor Jessé Guimarães, a Brasa enviou para Espinho Sergio França e família para ali se fixarem em definitivo e continuarem a atuar, vinculados à igreja Khárisma, sobretudo com os ciganos. No entanto, logo depois houve a separação entre a Khárisma e a Brasa e esta implantou-se institucionalmente em Espinho, tendo alguns portugueses, e majoritariamente os ciganos, como fiéis. ${ }^{22}$ Segundo o atual missionário da Brasa em Espinho, pastor Carlos Xavier, a separação foi tranquila, pois "entendeu-se que a igreja [Brasa] tinha um desafio de missões, um chamado para plantar uma igreja e começar um trabalho". ${ }^{23}$

No entanto, em 2005, por ocasião do retorno ao Brasil do pastor Sergio Martini, o segundo missionário da Brasa em Espinho, os ciganos, por sua vez, em torno de 25 pessoas, se retiraram da igreja Brasa sob a liderança de Rui Maia, que fundou, em 07/01/2006, a Igreja Pentecostal Shalom, cuja sede se localiza hoje em Vila Nova de Gaia. ${ }^{24}$

19 Esta igreja mantém desde a década de 1990 parcerias com igrejas inglesas. Portugal é o único país em que ela possui uma extensão institucional da igreja brasileira.

20 Recordo que, em Portugal e na Espanha, a igreja evangélica que mais congrega ciganos, embora não exclusivamente, é a Igreja Evangélica Filadélfia (Santos 2003; Cantón Delgado 2004).

21 Este afirma que se converteu ao Evangelho aos 18 anos de idade, na própria igreja Khárisma.

22 Possivelmente, situações pessoais envolvendo o pastor Ferreira e as autoridades policiais terão contribuído para a separação das igrejas.

23 Este pastor acrescenta que mantem até os dias atuais uma "relação saudável" com o pastor Ferreira, porque ele foi alguém que no início fez parte dos contatos e das conexões, "antes de a igreja [Brasa] nascer aqui".

24 Ironicamente, Rui Maia foi alçado à condição de pastor pela própria Igreja Brasa. Hoje a Shalom possui sete igrejas em Portugal e duas no exterior: na Alemanha, em Dortmund, e na Suíça, em Zurique. Além disso, possui células em Mônaco e na Inglaterra. Alguns jogadores de futebol, como o goleiro brasileiro Helton e os colombianos Falcao Garcia e James Rodrigues, integraram-se nesta igreja, dando maior visibilidade à mesma. Segundo Maia, hoje, no culto dominical da sede da igreja, em Gaia, comparecem cerca de 300 pessoas. No total, a igreja teria na atualidade cerca de 600 membros. 
Segundo Maia, a saída da igreja Brasa resultou de um chamado divino para fundar uma nova igreja e contou, para tanto, com a bênção do próprio pastor Jessé Guimarães. Destaca o fundador da Shalom que muito aprendeu com os pastores brasileiros, aos quais se diz bastante grato.

Embora o atual pastor da Brasa em Espinho destaque que "o povo cigano é bastante religioso e querem ficar juntos, com suas características, suas raízes, sua cultura", é claro que essa defecção foi na época bastante sentida pela Brasa, que imaginava ser possível integrar e acolher na igreja ciganos e outros portugueses. Na atualidade, e agora sob a liderança do pastor Xavier, o terceiro missionário radicado em Espinho, a Brasa possui em torno de 70 fiéis, 80\% deles sendo portugueses e os demais brasileiros, latino-americanos e angolanos.

Vale registrar que em Portugal a Igreja Brasa não se mantém isolada das demais igrejas evangélicas. Como refere o pastor Martini, "a gente não é daqueles fechados. E a gente luta para não ser isso". ${ }^{25}$ Por sua vez, o pastor Xavier também destaca ser muito importante manter relacionamentos interinstitucionais e interpessoais. ${ }^{26}$

Já em Roma encontramos a igreja brasileira Maanaim, cuja chegada na Itália ocorreu de forma semelhante à da Brasa em Portugal. Foi o pastor italiano Ugo Sottile, presidente da Convenzione Nazionale delle Assemblee di Dio Ministero Madureira, quem convidou, em janeiro de 2011 , o pastor brasileiro Edilson Avila e sua esposa Ana para colaborarem em sua igreja. Como disse em outro lugar (Oro 2014b), o início entre ambos foi cooperativo e amistoso. No entanto, com o passar dos meses, tensões e dificuldades de relacionamento começaram a surgir e, um ano após a sua chegada em Roma, Avila já não frequentava mais a igreja de Sottile.

As tensões entre ambos resultaram fundamentalmente de diferenças culturais, como o rigorismo no cumprimento dos horários dos cultos e um espaço maior para o louvor, isto é, a presença da emoção, reivindicada pelo missionário brasileiro. ${ }^{27}$

Diante desta nova situação, o pastor Avila, ao invés de retornar ao Brasil, implantou na Itália - após ter recebido em Roma a visita do fundador da sua igreja - uma célula da Igreja Maanaim, localizada no seu próprio apartamento, situado nos arredores de Roma. Ali, recebe uma vez por semana um pequeno

25 Conforme entrevista concedida a Mariana Picolotto em Porto Alegre em 1 1/05/2017. Os demais depoimentos deste pastor resultam desta entrevista. Para uma exposição mais detalhada sobre a implantação da igreja Brasa em Espinho, bem como das demais igrejas aqui mencionadas, ver Oro (2017).

26 Este pastor é um dos grandes incentivadores das reuniões mensais que pastores do Norte de Portugal realizam no âmbito da Comunhão de Pastores do Norte, antigo Conselho de Pastores do Norte. O objetivo dos encontros, que reúnem pastores de diferentes denominações e nacionalidades, diz ele, "é aproximar os laços entre os pastores, para que possam conversar e construir laços profundos de amizade".

27 Voltarei a este tema mais à frente. 
grupo de pessoas, pertencentes a diferentes nacionalidades, para a celebração de um culto, além de pastores de outras igrejas.

Portanto, as igrejas Brasa e Maanaim transnacionalizaram-se seguindo um modelo diferente daquele realizado pela Universal. Ambas chegaram na Europa a partir de convites e não por iniciativa própria. Porém, em ambos os casos ocorreu a ruptura com as parcerias portuguesa e italiana e a consequente instalação das mesmas em território europeu. Enfim, os líderes de ambas as igrejas, e novamente de forma diferenciada da Universal, estão abertos para cultivarem relações ecumênicas com outros missionários e igrejas, brasileiras ou não.

\section{Parceria inicial e dupla ruptura}

O terceiro modelo de transnacionalização religiosa é representado pela Missão Cristã Internacional (MCI), sediada em Mem Martins, nos arredores de Lisboa. Aproxima-se do anterior pelo convite inicial realizado por portugueses junto à igreja brasileira Luz para os Povos, mas distingue-se dele pelo fato de que os missionários chegados em Portugal, após alguns anos de atividade, se distanciaram tanto da igreja portuguesa quanto da brasileira, fundando uma nova denominação em solo português, a qual, porém, e de forma semelhante às igrejas Brasa e Maanaim, e diferentemente da Universal, está aberta a relações ecumênicas. Vejamos isto com mais detalhes.

A MCI foi fundada em Portugal em fevereiro de 1997 pelos pastores brasileiros Marcelo Almeida e Sidson Novais. Posto que o primeiro retornou ao Brasil em janeiro de 1999, o segundo assumiu sozinho a direção da igreja. Ambos os pastores, juntamente com outros mais, pertenciam no Brasil à igreja Luz para os Povos. ${ }^{28}$ Em março de 1995 chegaram a Portugal para, segundo Novais, "apoiar uma pequena igreja que existia [...]. Era uma pequena igreja, muito pequena, de portugueses".

Porém, esclarece Novais que "não deu muito certo a experiência, porque a igreja [Luz para os Povos] não estava preparada, não só no que se refere à questão de apoio de subsistência, financeiro, mas também em relação ao apoio ministerial mesmo, pastoral e de acompanhamento, de projeto". Quanto à igreja local, além de simples, "não tinha muitas semelhanças com a igreja do Brasil. Então houve um choque cultural". No dizer de Novais, "houve um choque de interesses, de objetivos, de tudo..."

Em consequência disso, surgiu um impasse: "ou nós voltávamos para a igreja de origem para continuar nosso papel lá, ou se nós ficássemos por aqui seria por conta própria".

28 A igreja Luz para os Povos é uma denominação pentecostal fundada em Goiânia, Brasil, em 1987. Possui atualmente cerca de 300 igrejas implantadas no Brasil e em outros países. A instituição adota o modelo 100\% Visão Celular, baseado na ideia da propagação da fé através de reuniões familiares. 
Neste momento, a equipe de missionários se desfez. A maioria retornou ao Brasil, mas Sidson Novais e Marcelo Almeida decidiram "começar um trabalho novo, mesmo do zero". Fundaram, então, a MCI, Missão Cristã Internacional. Considera que se trata de uma "igreja portuguesa, apesar de ser fundada por brasileiros".

Hoje, em todo Portugal, a MCI possui 11 igrejas estabelecidas e o culto matutino dominical, realizado na sede de Mem Martins, reúne cerca de 350 pessoas. Nas demais igrejas a frequência varia entre 20 e 80 pessoas. Ainda segundo o fundador, a membresia da igreja é multiétnica. Tanto assim que, segundo ele, a igreja "possui uma identidade assumida: somos uma igreja multiétnica", cuja composição seria de $45 \%$ de brasileiros, 35\% de portugueses e $20 \%$ de africanos".

A MCI integra formalmente a Aliança Evangélica Portuguesa, bem como a comunhão de igrejas pentecostais Fraternal-Comunhão Nacional de Igrejas e Organizações Pentecostais e Carismáticas - que agrega igrejas portuguesas, brasileiras e de outras nacionalidades. No ano de 2016, o pastor Novais era o presidente da Fraternal, e seus membros, entre 70 e 80 pastores, se reuniam uma vez por mês.

\section{Aliança e parceria duradouras}

O quarto modelo de transnacionalização religiosa é baseado na aliança e no trabalho colaborativo cumprido entre duas denominações que firmaram uma parceria, também não formalizada, e que a mantêm até o momento. É o que ocorre com a igreja brasileira Sal da Terra e a igreja portuguesa Reviver, uma parceria que existe há cerca de 20 anos.

A igreja Sal da Terra foi fundada em 1978, em Uberlândia, Minas Gerais, e possui como identidade institucional o cultivo da música e de outras expressões artísticas, especialmente junto aos jovens, e a atenção às alianças e às missões transculturais.

Em 2003, essa igreja firmou uma parceria com a igreja portuguesa Reviver. Esta, fundada em 2002, ${ }^{29}$ mas cujas origens remontam a 1996, com a Igreja Evangélica Assembleia de Deus, de Santo António dos Cavaleiros, também foi se construindo como uma instituição que privilegia o trabalho com os jovens, embora não exclusivamente, e está aberta para estabelecer alianças de colaboração com outras igrejas. Essa convergência de interesses fez com que ambas as instituições selassem uma parceria que se mantém ao longo dos anos.

O pastor João Fonseca Neto constitui a terceira família missionária da igreja Sal da Terra a cooperar com a igreja Reviver. Chegou a Portugal em 2014 e, 
segundo diz, "existe uma amizade entre as igrejas, uma parceria, de influência. Já foi gente daqui para lá e de lá para cá. É cooperação”.

Ambas as igrejas (Sal da Terra e Reviver) convergem no interesse de evangelizar os jovens, atraindo-os com apelos que lhes são caros, como música, dança e outras atividades. No dizer do pastor Neto, cerca de $60 \%$ a $70 \%$ dos jovens e demais membros da igreja Reviver são portugueses. Os demais provêm de outras nacionalidades, como angolanos, moçambicanos e cabo-verdianos. Duas seriam as famílias brasileiras que participam da igreja.

Um fato revelador da parceria exitosa entre ambas as igrejas pode ser visto no fato de que em maio de 2017 a igreja Reviver, ao comemorar 36 anos de existência, realizou um evento entre os dias 24 e 28 daquele mês, tendo como palestrantes dois pastores brasileiros, a saber, Ed Rene Kivitz, da Igreja Batista de Água Branca (IBAB), de São Paulo, e o pastor Paulo Junior, da Igreja Sal da Terra. Foi este último que iniciou e dinamizou a parceria da sua igreja com a igreja Reviver.

Vale registrar ainda que ambas as igrejas pertencem ao movimento "Ide às Nações" (Go to the Nations"), organização que desenvolve parcerias missionárias através de redes de relacionamento e que organiza uma conferência anual com o objetivo de estimular o trabalho de missões.

$\mathrm{O}$ que precede revela que estamos diante de um modelo de transnacionalização que diverge parcialmente dos anteriores, firmados pelas igrejas Brasa/ Maanaim e MCI, e, mais ainda, daquele estabelecido pela Igreja Universal. Isto porque as igrejas Sal da Terra e Reviver atuam há duas décadas em parceria e a mantêm como forma de cooperação. ${ }^{30}$

Se, por um lado, como acabamos de ver, as igrejas brasileiras referidas divergem acerca das estratégias de transnacionalização e das formas de atuação em território europeu, por outro lado, convergem quanto à ideia de adotarem determinadas práticas e narrativas que facilitem a sua integração nas culturas locais. É o que veremos na última parte deste texto.

\section{ACOMODAÇÕES ÀS CULTURAS LOCAIS}

Os missionários brasileiros são unânimes em afirmar que, apesar de integrarem a mesma cultura latina, Brasil, Itália e Portugal são portadores de culturas diferentes. Mesmo relativamente a Portugal, em razão do entrelaçamento histórico-cultural existente com o Brasil, as diferenças são importantes. Por isso, destaca, por exemplo, o pastor Xavier, que não pode um missionário vindo do Brasil "querer colocar um Brasil dentro de Portugal, fazer as coisas à moda do

30 Semelhante forma de atuação em parceria é praticada pela igreja Assembleia de Deus, de Almada, a qual, segundo a pastora Ana Mary Baizan, ocorre "não tanto com igrejas e mais com relacionamentos pessoais". 
Brasil". Também o pastor Novais enfatiza a necessidade de os brasileiros se adaptarem à cultura portuguesa. Por sua vez, o pastor português Pereira sublinha que, sem pontes com a cultura local, as igrejas brasileiras não terão êxito.

No exercício missionário na Europa os pastores apontam as questões da oferta e da emoção, além dos horários dos cultos, como os que mais exigem esforços de adaptação local.

\section{$O$ pedido de ofertas}

Os pentecostalismos, como se sabe, por um lado, assumiram do protestantismo histórico a obrigatoriedade moral de o fiel honrar o dízimo e, por outro lado, da mentalidade católica tradicional a associação entre obtenção da graça e sacrifício pessoal. Por isso mesmo, além de pedir o dízimo aos fiéis, os pastores do grande movimento pentecostal demandam ofertas financeiras diuturnamente aos fiéis como condição para a solução das suas aflições. No Brasil, é também sabido, igrejas neopentecostais, capitaneadas pela Universal, exacerbam os pedidos financeiros, tendo, em consequência do alto montante de ofertas recebidas, construído verdadeiros impérios econômicos, não sem provocar grandes controvérsias públicas e até mesmo processos judiciais. Outras igrejas são mais comedidas, mas sempre inserem a oferta na lógica do do ut des, ou seja, da reciprocidade.

Ora, os missionários brasileiros na Europa notam que enfrentam resistências em relação ao pedido de ofertas. Mas não somente eles. O pastor Sottile, na Itália, por exemplo, afirmou que "os italianos não estão assim dispostos a ofertar". Igualmente, o pastor português Pereira afirmou que "nesta questão tem que ir devagar". Por isso mesmo, pastores brasileiros como Xavier, Sidson e Avila revelaram que solicitam ofertas, mas sem exageros. Outros, como os portugueses Nuno e Ana Mary, da Assembleia de Deus, sublinharam que também solicitam ofertas, mas confessaram ter sido preciso primeiramente mudar a mentalidade dos portugueses para entenderem a relação existente entre oferta e eficácia desejada. Enfim, pastores de igrejas como a Universal e a Mundial tendem a manter na Europa o mesmo discurso reproduzido no Brasil, que defende a equivalência entre o montante da oferta e o tamanho da fé.

Seja como for, de uma forma geral os missionários repetem que, enquanto no Brasil não precisam de muito esforço para justificar o pedido de ofertas, pois os fiéis entendem a sua importância, na Europa precisam ser mais comedidos diante da resistência cultural que enfrentam. Em outras palavras, se no Brasil, mas não somente, o pentecostalismo investe na Teologia da Prosperidade, que aproxima o religioso e o econômico, sacralizando, de certa forma, o mercado e os bens materiais, especialmente o dinheiro, chegando ao ponto de estabelecer uma relação entre compromisso de fé e desprendimento financeiro, na Europa esta perspectiva não é bem acolhida, posto que ali prevalece a mentalidade que tende a separar religião e economia, assim como religião e política. 


\section{A expressão da emoção}

O louvor durante os cultos, que implica na expressão da emoção, constitui um dos pontos mais problemáticos encontrados pelos missionários brasileiros estabelecidos na Itália e em Portugal.

De fato, apesar de em ambos os países os missionários lidarem com uma membresia pluriétnica, revelam que a resistência à manifestação emocional é tal que os obriga a exercerem um controle, tanto sobre sua própria performance como pregadores, quanto sobre as práticas corporais dos fiéis, diferentemente do que ocorre no Brasil, onde o louvor é grandioso e a questão emocional flui naturalmente.

O pastor italiano Sottile é enfático ao afirmar que a cultura italiana não aceita o louvor exacerbado. Esta prática, segundo ele, guarda uma relação com a pobreza. Haveria, para ele, um vínculo entre emocionalidade e prodígios (curas, milagres), algo aceitável num país como o Brasil, mas não na Itália (Oro 2014b).

Em Portugal, o espaço do louvor nas reuniões também foi veiculado pelos brasileiros como algo sensível, mas não com a mesma intensidade apontada na Itália. Mas também ali não flui como no Brasil. Assim, por exemplo, um pastor da Igreja Mundial em Lisboa afirmou: "Aqui [em Portugal] é diferente. É mais fácil no Brasil do que aqui”.

Porém, os pastores brasileiros que conhecem a cultura anglo-saxônica percebem uma diferença entre o que lá ocorre em relação aos países latinos. Diz, a este propósito, por exemplo, o pastor Novais: "Eu já preguei em outros países, no Norte da Europa, e senti realmente essa frieza em relação a expressar as emoções; mas nos países latinos não sinto muito isso". ${ }^{31}$ Por sua vez, o pastor Bazerque também vê uma diferença cultural em relação aos ingleses. Diz ele: "A presença do emocional é uma coisa muito latina. Aqui nas igrejas [do Brasil] as pessoas se abraçam, se beijam; os ingleses, eles firmam o braço pra tu não chegar muito perto. Te seguram bem assim, pra que não chegue".

Essa diferença cultural, segundo esse pastor, precisa ser levada em consideração pelos missionários brasileiros estabelecidos na Europa. Mas, por sua vez, os pastores portugueses também referiram o cuidado que precisam ter em

31 Para o sociólogo italiano Pino Lucà Trombetta (2013: 23), a dificuldade europeia de aceitar e lidar com a emoção no campo religioso resulta, em primeiro lugar, de uma longa hegemonia das igrejas católica, protestante e ortodoxa, que produziram "um habitus que respeita em grande medida o modo pelo qual a religião é definida pelas elites religiosas", dotando as pessoas de categorias cognitivas capazes de fazê-las distinguir o que é religião do que é falsificação. Nesta perspectiva europeia torna-se difícil aceitar a mistura entre corpo e espírito, fé e exaltação psíquica, liturgia e espetáculo, assim como a relação entre religião e trabalho, religião e saúde, religião e economia, religião e bem-estar psíquico, presentes no modo de ser religioso do pentecostalismo em geral. Em segundo lugar, prossegue o autor, falta à Europa o esforço de “'reapropriar-se da própria história’, que é uma das matrizes do sucesso pentecostal nos países ex-coloniais”. 
relação à exaltação emocional durante os cultos. E atribuem a reticência portuguesa ao louvor à importância histórica da cultura católica no país, a qual considera, no dizer do pastor Rodrigues, "a igreja como lugar de silêncio", ou, de acordo com o pastor Fernandes, da Assembleia de Deus, "a igreja como local de reverência”. Por isso mesmo, complementa a pastora Ana Mary, da mesma denominação de Fernandes, o louvor consiste num aprendizado, pois implica numa "mudança de mentalidade", mudança de atitude corporal no recinto religioso.

\section{O cumprimento dos horários dos cultos}

Outro ponto que choca os missionários brasileiros e os obriga a se acomodarem às culturas locais repousa na necessidade do cumprimento dos horários dos cultos. Se no Brasil não há rigidez nos horários, na Europa, diz o pastor Neto, "tem horário para começar e horário para terminar. Isto é fundamental. Isto é um valor: começar no horário e terminar no horário. Aí é um lado que a gente tem que aprender, como brasileiro".

O pastor Novais, por sua vez, confessa que aprendeu em Portugal a levar a sério os horários dos cultos. E diz que o faz com tal empenho que, quando o descumpre, se escusa diante dos fiéis. Diz ele: "quando no culto do domingo se passa do meio-dia, a gente pede desculpa e fala: 'hoje, por causa das atividades extras, passamos quinze minutos', e tal".

Outros pastores, como o da Mundial e da Universal, justificam a necessidade do cumprimento do horário dizendo, simplesmente: “porque aqui [na Europa] é assim". Igualmente o pastor Bazerque, da igreja Brasa, afirma que, embora se brinque sobre a pontualidade britânica, "em Portugal também gostam do horário. Tá marcado para tal hora, tal hora tem que se fazer".

As explicações dos missionários para a necessidade do cumprimento dos horários são de ordem cultural. O pastor Xavier avança dois aspectos: em primeiro lugar, os cultos não podem coincidir com os horários das refeições, "porque o português prima muito pela questão da refeição e da família"; em segundo lugar, pela importância da tradição católica, a qual marcou de tal forma a cultura religiosa portuguesa que um culto evangélico, da mesma forma que a missa católica, precisa ter horário de início e de término. O pastor Rodriguez, da igreja Hillsong, acrescenta que cumprir os horários demonstra a organização e a seriedade da igreja.

Tudo o que precede evidencia, como também constatou Gracino Junior, que os missionários brasileiros estabelecidos em Portugal - e na Europa - se esforçam para se adaptarem "aos contextos sociossimbólicos locais, negociando, captando sentidos e flexionando seu discurso para comportar suas demandas" (2016: 146).

Mas há também aspectos da cultura brasileira que, no dizer dos pastores brasileiros, poderiam ser integrados pelos europeus. Por exemplo, segundo o 
pastor Neto, "nós brasileiros podemos influenciar os portugueses com a espontaneidade. Acho que isto é a melhor troca. Um lado pode aprender com o outro". Também o pastor Locatelli, da Assembleia de Deus, reforça a noção de aprendizados mútuos. Para ele, pode-se muito bem combinar o "entusiasmo do brasileiro e a organização dos europeus". ${ }^{32}$

\section{CONSIDERAÇÕES FINAIS}

Este texto discorreu sobre três tópicos. O primeiro explorou a política dos significados agregados pelos missionários e igrejas brasileiras para se transnacionalizarem para a Europa, realizando, assim, a "missão invertida". Sobressaiu uma narrativa fartamente enunciada, a saber: a obrigação moral dos "filhos" brasileiros de contribuírem para a recristianização dos "pais" europeus, posto que na Europa predominaria hoje a indiferença religiosa. Mas, além deste, apareceram outros sentidos da transnacionalização, menos propalados pelos agentes religiosos brasileiros estabelecidos na Europa, como a possibilidade de obtenção de benefícios econômicos, a abertura para o mundo e, sobretudo, a elevação de status e de legitimação num contexto religioso concorrencial "local", justamente por fecharem parcerias, mesmo que informais, organizarem-se em redes e enviarem missionários para igrejas de um continente tão importante como o europeu.

O segundo tópico mostrou que os fluxos transnacionais movidos pelas igrejas brasileiras para a Europa permitem montar uma tipologia de transnacionalizações religiosas, na qual, até o momento, minha etnografia permite montar quatro modelos diferentes.

O primeiro modelo advém do modo de atuação de igrejas neopentecostais, capitaneadas pela Igreja Universal. Trata-se de igrejas que empreendem a transnacionalização por iniciativa própria, após um estudo prévio do mercado religioso no exterior e, uma vez ali estabelecidas, adotam o princípio do exclusivismo religioso, da ação isolada e autônoma na disputa por fiéis, seguindo a lógica da oferta de serviços religiosos. Este modelo aproximar-se-ia da "transnacionalização pelo alto", ou seja, da globalização, conforme foi esclarecido no início do texto.

O segundo modelo é representado pelas igrejas Brasa e Maanaim. Caracteriza-se por igrejas que se transnacionalizam a partir de convites recebidos de agentes religiosos europeus, mas que, após alguns meses ou anos, desfazem a parceria, gerando uma situação inicialmente não prevista pelas igrejas missionárias, qual seja a de se instalarem institucionalmente nos países em que foram 
convidadas. As igrejas deste modelo mantêm convivência ecumênica, diferentemente do isolacionismo observado no modelo anterior.

O terceiro modelo resulta da análise da Missão Cristã Internacional (MCI). Novamente, o impulso inicial da transnacionalização provém de um convite para atuar no exterior. Porém, após um momento de colaboração, os pastores rompem duplamente, com a igreja missionária brasileira e com a igreja receptora estrangeira, criando, eles próprios, uma nova denominação, conectada com outras igrejas locais.

Enfim, o quarto modelo advém da parceria de quase 20 anos firmada entre a igreja brasileira Sal da Terra e a igreja portuguesa Reviver. Neste caso, trata-se de uma parceria duradoura, fruto, em grande medida, da convergência de interesses, ou seja, no caso analisado, a evangelização dos jovens e a participação em redes evangélicas transnacionais.

Os três últimos modelos possuem em comum a noção de parceria, mesmo que informal, estabelecida individual ou institucionalmente, não passando, assim, pela burocracia estatal, sendo condizente, desta forma, com a noção de "transnacionalização por baixo".

O terceiro tópico versou sobre as adaptações litúrgicas empreendidas pelos missionários e igrejas brasileiras transnacionalizadas em face de tensões atribuídas às diferenças de códigos culturais existentes entre a dita "cultura brasileira" e a "cultura europeia", com repercussão no campo religioso.

Neste sentido, o gesto de realizar a oferta financeira, em que pese a sua simbologia no pentecostalismo - enquanto mediadora do sagrado e mensuradora da fé do fiel - não encontra total receptividade na mentalidade europeia, que tende a não aproximar plenamente dinheiro e religião. Isto obriga os missionários a atenuarem o pedido de ofertas e a investirem em argumentos justificativos, prática esta, porém, menos empreendida pelas megaigrejas neopentecostais, que tendem a assumir abertamente as demandas por ofertas. Igualmente, há resistências culturais na Europa acerca do louvor, algo importante no pentecostalismo brasileiro, mas que na Europa obriga os missionários, da mesma forma que os pentecostais nativos, a procederem à sua domesticação, empreendendo até mesmo uma pedagogia do louvor. Enfim, reconhecem os missionários que o cumprimento dos horários dos cultos é tido como um valor na Europa, diferentemente do que ocorre no Brasil, devendo eles se acomodarem a essa nova realidade. Assim procedendo, os missionários brasileiros radicados na Europa - apesar de portarem uma visão essencialista das culturas - alimentam a ideia de que "a gente pode se completar", segundo as palavras do pastor João Neto, da igreja Sal da Terra. 


\section{BIBLIOGRAFIA}

ALVES, Daniel, 2011 , Conectados pelo Espírito: Redes Pessoais de Contato e Influência entre Líderes Carismáticos e Pentecostais ao Sul da América Latina. Porto Alegre, PPGAS/UFRGS, tese de doutorado.

ARGYRIADIS, Kali, et al., 2012, Religions transnationales des suds: Afrique, Europe, Amériques. Paris, L'Harmattan / Louvain-la-Neuve, Academia.

BADIE, Bertrand, e Marie-Claude SMOUTS, 1995, Le retournement du monde: sociologie de la scène internationale. Paris, Presses de la Fondation Nationale des Sciences Politiques/ /Dalloz.

CANTÓN DelgADO, Manuela (org.), 2004, Gitanos Pentecostales: Una Mirada Antropológica a la Iglesia Filadelfia en Andalucía. Sevilla, Ediciones de Andalucía.

CAPONE, Stefania, e André MARY, 2012, "Les translogiques d'une globalisation religieuse à l'envers", em Kali Argyriadis et al., Religions transnationales des suds: Afrique, Europe, Amériques. Paris, L'Harmattan/Louvain-la-Neuve, Academia, 27-45.

CARRANZA, Brenda, e Cecilia MARIZ, 2013, "Canção nova: catolicismo tipo exportação e missão reversa”, entrevista de Márcia Junges, IHU: Revista do Instituto Humanitas Unisinos, 424: 27-31.

CARRANZA, Brenda, e Cecilia MARIZ, 2016, "Canção nova: catolicismo tipo exportação e missão reversa”, em Cristina Rocha e Manuel A. Vásquez (orgs.), A Diáspora das Religiões Brasileiras. Aparecida, Editora Ideias \& Letras, 149-180.

FRESTON, Paul, 2010, "Reverse Mission: a discourse in search of reality?", Pentecostudies, 9 (2): 153-174.

FRIGERIO, Alejandro, 2013, "A transnacionalização como fluxo religioso na fronteira e como campo social: umbanda e batuque na Argentina", Debates do NER, 23: 15-57.

GABRIEL, Eduardo, 2010, Catolicismo Carismático Brasileiro em Portugal. São Paulo, Universidade de São Paulo, tese de doutorado.

GRACINO JUNIOR, Paulo, 2016, A Demanda por Deuses: Globalização, Fluxos Religiosos e Culturas Locais nos Dois Lados do Atlântico. Rio de Janeiro, Eduerj / Faperj.

GUARNIZO, Luis Eduardo, e Michael Peter SMITH, 1998, “The locations of transnationalism", Comparative Urban and Community Research, 6: 3-31.

MAFrA, Clara, 2002, Na Posse da Palavra: Religião, Conversão e Liberdade Pessoal em Dois Contextos Nacionais. Lisboa, Imprensa de Ciências Sociais.

MAFRA, Clara, 2003, "A Igreja Universal do Reino de Deus em Portugal”, em Ari Pedro Oro, André Corten e Jean-Pierre Dozon (orgs.), Igreja Universal do Reino de Deus: Os Novos Conquistadores da Fé. São Paulo, Editora Paulinas, 165-176.

MARY, André, 2008, "Africanité et Christianité: une interaction première", Archives de Sciences Sociales des Religions, 143: 9-31.

ORO, Ari Pedro, 2014a, "South American evangelicals re-conquest of Europe", Journal of Contemporary Religion, 29: 219-232.

ORO, Ari Pedro, 2014b, "Igrejas evangélicas brasileiras na Itália: recorrências e tensões", Estudos de Religião, 28 (2): 102-114.

ORO, Ari Pedro, 2017, “Transnacionalização evangélica brasileira para Portugal: tipologia e acomodações”, Ciencias Sociales y Religión, 26: 14-51.

ORO, Ari Pedro, e Daniel ALVES, 2015, "Encontros globais e confrontos culturais: o pentecostalismo brasileiro à conquista da Europa”, Dados, 58 (4): 95 1-980. 
ORO, Ari Pedro, Carlos Alberto STEIL, e João RICKLI (orgs.), 2012, Transnacionalização Religiosa: Fluxos e Redes. São Paulo, Terceiro Nome.

ORO, Ari Pedro, e Marcelo TADVALD, 2015, "A Igreja Universal do Reino de Deus e a reconfiguração do espaço público religioso brasileiro”, Ciencias Sociales y Religión, 23: 76-1 13. PORDEUS JUNIOR, Ismael, 2009, Portugal em Transe: A Transnacionalização das Religiões Afro-Brasileiras: Conversão e Performances. Lisboa, Imprensa de Ciências Sociais.

ROCHA, Cristina, e Manuel A. VÁSQUEZ, 2016, "Introdução", em Cristina Rocha e Manuel A. Vásquez (orgs.), A Diáspora das Religiões Brasileiras. Aparecida, Editora Ideias \& Letras, 7-38.

RODRIGUES, Donizete, e Marcos SILVA, 2014, “Imigração e pentecostalismo brasileiro na Europa: o caso da Igreja Universal do Reino de Deus”, Revista Angolana de Sociologia, 13: 97-113.

RUIZ, Jesus Garcia, e Patrick MICHEL, 2012, Et Dieu sous-traita le salut au marché. Paris, Armand Colin.

SANTOS, Ana Paula, 2003, "Iglesia Evangélica de Filadelfia de Portugal", em Anders Ruuth (org.), Rite and Power. Uppsala, Swedish Institute of Mission Research, 145-148.

SARAIVA, Clara, 2010, "Afro-Brazilian religions in Portugal: bruxos, priests and pais de santo", Etnográfica, 14 (2): 265-288.

SARAIVA, Clara, 2017, "Orixás across the Atlantic: the Diaspora of Afro-Brazilian religions in Europe”, em Bettina Schmidt e Steven Engler (orgs.), Handbook of Contemporary Religions in Brazil. Leiden, Brill, 320-332.

Trombetta, Pino Lucà (org.), 2013, Cristianesimi senza Frontiere: Le Chiese Pentecostali nel Mondo. Roma, Borla.

VILAÇA, Helena, 2013, "Novas paisagens religiosas em Portugal: do centro às margens", Didaskalia, XLIII (1-2): 81-114.

VILAÇA, Helena, 2016, "Prefácio”, em Paulo Gracino Junior, A Demanda por Deuses: Globalização, Fluxos Religiosos e Culturas Locais nos Dois Lados do Atlântico. Rio de Janeiro, Eduerj/ /Faperj, 15-19.

Receção da versão original / Original version

$2017 / 10 / 28$

Aceitação / Accepted

$2018 / 04 / 16$ 